NASA Technical Memorandum 105866

\title{
Environmental Interactions and the SP-100 Power System
}

Dale C. Ferguson

Lewis Research Center

Cleveland, Ohio

January 1993 


\section{DISCLAIMER}

This report was prepared as an account of work sponsored by an agency of the United States Government. Neither the United States Government nor any agency Thereof, nor any of their employees, makes any warranty, express or implied, or assumes any legal liability or responsibility for the accuracy, completeness, or usefulness of any information, apparatus, product, or process disclosed, or represents that its use would not infringe privately owned rights. Reference herein to any specific commercial product, process, or service by trade name, trademark, manufacturer, or otherwise does not necessarily constitute or imply its endorsement, recommendation, or favoring by the United States Government or any agency thereof. The views and opinions of authors expressed herein do not necessarily state or reflect those of the United States Government or any agency thereof. 


\section{DISCLAIMER}

Portions of this document may be illegible in electronic image products. Images are produced from the best available original document. 


\title{
ENVIRONMENTAL INTERACTIONS AND THE SP-100 POWER SYSTEM
}

\author{
Dale C. Ferguson \\ National Aeronautics and Space Administration \\ Lewis Research Center \\ Cleveland, Ohio 44135
}

\section{SUMMARY}

The Civil Space Technology Initiative (CSTI) High-Capacity-Power Environmental Interactions Program has made great progress in defining and evaluating the interactions of the SP-100 power system with its expected ambient environments. The NASCAP/LEO and POLAR computer codes demonstrated that local electric fields at the user interface module are high. Therefore, particular attention must be paid to geometries and materials in this region to prevent arcing at conductor-insulator junctions in low Earth orbit (LEO).

NASCAP/LEO and EPSAT computer models revealed that SP-100 payloads float about $100 \mathrm{~V}$ negative of the LEO plasma. In addition, ground tests and modeling done for the Space Station Freedom Electrical Grounding Tiger Team found that dielectric coatings often break down at such voltages in a plasma. Thus, surface coatings for SP-100 payloads should be carefully selected. Sputtering may also be a concern for long-duration missions in LEO at these voltages. Much work has been done on a sputtering mc del to evaluate surface material loss rates on $\mathrm{SP}-100$ payloads.

In ground plasma chamber tests of cables and cable insulators at SP-100 voltages, parasitic power losses due to the plasma current collected from possible pinholes or coating defects were quantified and shown to be small. Modeling revealed that the power loss from currents to other surfaces is also small.

The atomic oxygen durability of SP-100 materials and coatings continues to be investigated in ground tests. In the upcoming Evaluation of Oxygen Interaction with Materials (EOIM-3) Shuttle flight experiment, a host of SP-100 materials will be evaluated for atomic oxygen durability in LEO.

Finally, an evaluation of the interactions of the SP-100 power system with lunar and planetary environments has started. At a workshop on chemical and electrical interactions on Mars recently held at the NASA Lewis Research Center, many of primary interactions were identified. In low Mars orbit, many of the concerns now being addressed for LEO will be important, and the results of the present Environmental Interactions Program will be very relevant. On the surfaces of the Moon and Mars, new issues arise. A workshop report has been published.

\section{INTRODUCTION AND OVERVIEW}

Interactions of spacecraft with their environments have traditionally been important in terms of reliability. The Van Allen radiation belts were discovered from the saturation (temporary shutdown) of a Geiger counter on Explorer I (Vampola, 1980). Anomalies in spacecraft operation in geosynchronous orbit (GEO) were often traced to spacecraft charging and arcing during solar substorm events: the Marecs-A spacecraft experienced a power loss on part of its solar arrays as a result of this phenomenon (Frezet et al., 1989). Spacecraft encountering the powerful radiation belts of Jupiter underwent single-event upsets because of their hard radiation environment. As a result, solar cells for space applications are routinely covered with coverslips to reduce radiation damage. 
More recently, high-voltage spacecraft in low Earth orbit (LEO) experienced significant interactions with their environment. The Upper Atmospheric Research Satellite (UARS), with a power system providing $100 \mathrm{~V}$ coming out of an eclipse, charged to $90 \mathrm{~V}$ negative of its surrounding plasma because of plasma interactions with its solar arrays (D. Winningham, 1992, South West Research Institute, San Antonio, TX, private communication). This charging made data interpretation from some of its instruments difficult. Because Space Station Freedom would float an estimated $140 \mathrm{~V}$ negative of its surrounding plasma and would be at risk for sputtering and arcing damage, a plasma contactor to control its floating potential has been baselined (R. Moorehead, 1992, NASA SSF Program Office, Reston, VA, private communication).

The SP-100 power system's interaction with its environment must be considered when payloads and missions are planned. The types of interactions it experiences depend on the environments encountered in its missions (Jongeward et al., 1987). Detailed information about spacecraft environmental interactions in different regimes is available in several published works.

In the GEO environment, the major interaction of concern is differential charging of different parts of a spacecraft, which leads to high electric fields and arcing between spacecraft components (Herr, 1991). In GEO, the ambient-plasma thermal current densities are insufficient to rapidly discharge spacecraft surfaces. Although there are many sources of charging (i.e., the photoelectric effect, secondary electron emission, etc.), most arcs result from charging during solar substorm events. At these times, the Earth's geomagnetic tail, laden with particles from a sudden solar wind transient, undergoes field line breakage and reconnection, which accelerates electrons to thousands of electron volts. These electrons charge insulating spacecraft surfaces and increase electric fields to adjacent conductors beyond a breakdown level leading to arcing (Ferguson, 1986). The resultant arc currents, traveling through spacecraft conductors, upset electronic components and induce spurious signals. A common design solution for GEO is to coat all outside spacecraft surfaces with conducting materials to eliminate the possibility of differential charging (Purvis et al., 1984).

In LEO, absolute charging of spacecraft surfaces with respect to the surrounding plasma is a great concern. Because LEO thermal plasma current densities are high, surfaces do not ordinarily differentially charge, and total absolute potentials are rapidly bled off by collected plasma currents. However, some spacecraft impose differential charging on themselves by using distributed high voltages. Efficient power distribution requires either massive conducting cables (Ferguson, 1989) or high voltages, the latter being chosen by SP-100 designers and most others (Josloff, 1988a and Josloff, 1988b). Spacecraft surfaces float at potentials which result in no net current collection from the plasma. If conductors at different voltages are not exposed to the space plasma, all spacecraft surfaces will float within a few volts of the surrounding plasma potential. If conductors of similar area but different voltages are exposed to the plasma, a rule of thumb is that the most negative surfaces will float negative of the plasma by about 90 percent of the total voltage difference between the surfaces. As will be seen in the section Floating Potentials, a payload of the SP-100 power system will likely float about $100 \mathrm{~V}$ negative of a LEO plasma (see fig. 1 from Jongeward et al., 1990). Locally, insulating surfaces will charge only a few volts negative of the surrounding plasma.

Arcs in LEO occur from conductor-insulator junctions (including holes in cable insulation) when the conductor is highly negative of the surrounding plasma, or they can occur from anodized or other dielectric surfaces when the underlying conductor is at a negative potential higher than the dielectric breakdown strength of the coating (Ferguson, Snyder, and Carruth, 1990). Arc currents may flow out into the surrounding plasma, the return currents being distributed over wide areas of other spacecraft surfaces. Arcs can also occur through the plasma between closely spaced conductors at differing voltages (D.B. Snyder, 1991, NASA Lewis Research Center, Cleveland, $\mathrm{OH}$, private communication). Conducting 
surfaces highly negative of the plasma attract high-energy ions and are at risk for sputtering (Ferguson, Snyder, and Carruth, 1990). Nearby surfaces may acquire a sputtered conducting coating, which will change their electrical, optical, and thermal properties. If high positive potentials occur, electrons will be collected, leading to localized heating and significant power drains (Stevens, 1978). Conductors may become exposed by the impact of micrometeoroids and/or other debris, dielectric breakdown, atomic oxygen degradation, etc.

The neutral spacecraft environment is also important. Chemically active species such as the predominating atomic oxygen of LEO can oxidize and damage surfaces, especially in the ram direction where the spacecraft ram velocity simulates a high-energy beam. Volatile oxidation products may be lost, leaving a surface denuded of its protective coverings. Chemically active ions are attracted by charged spacecraft surfaces, and their reaction rates increase with energy (Ferguson, 1990). Such considerations are important mainly for low planetary orbits such as LEO but may also be important in a low Mars orbit.

In low-pressure neutral atmospheres, as on the Martian surface and areas surrounding lunar bases, other interactions may be important: the Paschen breakdown of atmospheric gases and arcing from dusty surfaces (Kolecki and Hillard, 1992).

The CSTI High-Capacity-Power Environmental Interactions Program has made great progress in defining and evaluating the interactions of the SP-100 power system with its expected ambient environments. A preliminary report of important system interactions was published by the S-Cubed Division of Maxwell Laboratories (Jongeward et al., 1987); however, the present report describes recent results and activities in many major areas.

\section{SP-100 GROUNDING SCHEME AND SURFACE POTENTIALS}

SP-100, a 200-V system, is divided into two halves with the structure ground in the middle (Brewer, 1988). At the user interface module (UIM), the payload is connected to the power system. The payload experiences a full 200-V difference and is grounded to the negative end of the power supply. Figure 2 (adapted from Brewer, 1988) shows a connection between the SP-100 structure ground and the payload structure ground through a resistor. As presently configured, to prevent a very large power loss in the resistor, its value must be high enough to make the payload structure ground be $100 \mathrm{~V}$ negative of the SP-100 structure ground. Thus, in the UIM where the structures are attached, there will be a 100-V difference in the structure potentials. Attached structures must be connected with an insulating material of sufficient thickness to stand off this difference. However, the surrounding plasma also has a small region of high electric fields (a sheath). The NASCAP/LEO and POLAR computer codes showed that local electric fields at and near the user interface module are high (Jongeward et al., 1990). Attention must be paid to geometries and materials in this region to prevent arcing at conductor-insulator junctions in LEO. In particular, conductors known to have a plasma arcing threshold higher than $100 \mathrm{~V}$ must be used.

Materials such as silver-coated interconnects and silicon are commonly used in solar cells, and they do not arc at voltages lower than about $200 \mathrm{~V}$ (Ferguson, 1986). On the other hand, from ground plasma tests, copper has been inferred to arc at a much lower voltage, possibly as low as $40 \mathrm{~V}$ (D.B. Snyder, 1991, NASA Lewis Research Center, Cleveland, OH, private communication). Arcing thresholds for other materials have not yet been determined. There is some evidence that arc rates are higher for materials that absorb and/or adsorb water or other volatile materials (Upschulte et al., 1991). Such materials, including some types of adhesives and polymeric materials, should be avoided in the UIM joint. Geometry can influence plasma arcing as well, and geometries that help to prevent ions from entering the 
conductor-insulator region are preferred. The SPEAR-I rocket flight avoided arcing at voltages much higher than $100 \mathrm{~V}$ by a clever exclusion of plasma ions from conductor-insulator junctions (Katz, 1989). Designs that accomplish this exclusion use codes such as NASCAP/LEO and require extensive computer calculations of particle orbits in the anticipated geometries and electric fields.

\section{FLOATING POTENTIALS}

NASCAP/LEO and EPSAT computer models demonstrated that SP-100 payloads float about $100 \mathrm{~V}$ negative of the LEO plasma (Jongeward et al., 1990). This situation exists because of the large area of exposed conductor in the power system that effectively grounds it to the surrounding plasma. The grounding scheme used in SP-100 contributes this effect by placing the payload $100 \mathrm{~V}$ negative of the power system. The small payload area then must collect a current of sluggish ions to balance the current of mobile electrons easily collected by the large power system area. As a result, the power system will float near the plasma potential, pushing the payload far negative.

For LEO missions the same sort of arcing considered for the UIM joint can be avoided by ensuring that the payload surfaces not have exposed conductors or exposed conductor-insulator junctions.

For GEO missions, fully conductive surfaces should be used everywhere to avoid differential charging (Purvis et al., 1984).

\section{DIELECTRIC BREAKDOWN}

Ground tests and modeling done for the Space Station Freedom Electrical Grounding Tiger Team revealed that dielectric coatings often break down at $-100 \mathrm{~V}$ in a LEO plasma (Grier and Domitz, 1991). Rated dielectric strengths and strengths measured in an atmosphere were not consistently reached before breakdown in the plasma. It is suspected that this result can be attributed to the coating porosity which allows plasma ions to come much closer to the underlying conductor than the nominal dielectric coating thicknesses. Even coatings with rated dielectric strengths of much more than $100 \mathrm{~V}$ seemed porous enough to the plasma ions to exhibit real dielectric strengths of less than $100 \mathrm{~V}$. Because the SP-100 payload will be at about $-100 \mathrm{~V}$ with respect to its surroundings, it is important that dielectric coatings used on its outer surfaces be strong enough to stand off $100 \mathrm{~V}$ in a plasma. Thus, surface coatings for SP-100 payloads must be carefully selected. In particular, the chromic acid anodization commonly used on aluminum exposed to space often lacks sufficient strength to stand off $100 \mathrm{~V}$ in a plasma. Thickening the coating is not usually an option because the thermal properties of such coatings are influenced. Sulfuric acid anodized coatings have greater dielectric strengths but very different thermal properties. For LEO missions, it is recommended that sulfuric acid anodization be used in regions where thermal control is not an overriding concern and that atomic-oxygen-protected, aluminized kapton blankets (kapton surface on the outside) of $1000-\mathrm{V}$ dielectric strength be used on all other outside surfaces of the payload.

\section{SPUTTERING}

In LEO, sputtering is a concern for long-duration missions with the payload at high negative voltages. A complicating factor is that the sputtering species is atomic oxygen; little information is available about atomic oxygen or about the chemical effects that may contribute to sputtering rates. Much work has been done on a sputtering model to help evaluate surface material loss rates on SP-100 payloads in LEO (Eck, Chen, and Hoffman, 1991). From measurements of low-energy sputtering by atomic oxygen made by Eck and others at Case Western Reserve University has come a theory (Eck, 1992) of low- 
energy sputtering which better agrees with all known low-energy measurements. One distinguishing characteristic of Eck's theory is that there is no absolute threshold for sputtering; rather, at low energies the rate is determined by the thermal tail of the surface material atom velocity distribution. Sputtering rates are a strong function of the surface voltage. Because the voltages on SP-100 are not in the kilovolt range (which would imply high sputtering rates), sputtering will only be important for mission times as long as years in a high-density plasma such as that in LEO or low Mars orbit. Sputtering may also be a long-term problem in the lunar environment if locally produced environmental plasmas have a high enough density. Whenever long life is required in a high-density plasma environment, surfaces should be insulated to prevent high-potential conductors from directly contacting the plasma.

The Space Station Freedom Electrical Grounding Tiger Team demonstrated that wherever micrometeoroids, debris, or manufacturing defects produce small pinholes in the insulators the sputtering rate will be greatly increased by ions focusing on the pinhole. Underlying conductors must be sufficiently thick to withstand puncturing at accelerated sputtering rates (see fig. 3, adapted from Snyder and Herr, 1991). Materials with low sputtering rates may also be used if they satisfy thermal, atomic oxygen, structural, and other requirements. Optical, thermal, or other specialized coatings in the line of sight to the sputtering pinhole become coated with the sputtered material over a long period of time. Hence, it is desirable to place such surfaces out of the line of sight.

\section{PARASITIC POWER DRAIN}

Wherever biased, exposed conductors exist, plasma currents will be collected. In the ground plasma chamber testing of cables and cable insulators at SP-100 voltages, parasitic power losses due to the plasma current collected from pinholes or coating defects were quantified and shown to be small. In particular, Grier and Domitz (1989) tested several candidate cable materials and showed that below $+200 \mathrm{~V}$ collected currents remained negligible. At voltages of $200 \mathrm{~V}$ and above, insulation pinholes exhibited snapover effects. However, it is unlikely that any SP-100 surfaces will be at potentials greater than $100 \mathrm{~V}$ above the plasma potential so snapover is not expected to occur. NASCAP/LEO modeling has shown that the power loss from currents to other surfaces is small compared to the total delivered current and thus the percentage efficiency loss is also small (Jongeward et al., 1990). In general, for every square meter of exposed payload conductor in LEO a parasitic structure current of about $1 \mathrm{~mA}$ may be expected. Thus, for a payload with a surface area of about $100 \mathrm{~m}^{2}$, only $100 \mathrm{~mA}$ of structure current may be extracted from the power supply capacity as compared to the $500 \mathrm{~A}$ that the power source may deliver at $200 \mathrm{~V}$ and $100 \mathrm{~kW}$.

\section{ATOMIC OXYGEN DURABILITY}

Materials exposed to atomic oxygen (the predominant species in LEO) are subject to rapid oxidation. In contrast to sputtering by ions in LEO where the sputtering rate per incident particle may be 0.1 and the flux of sputtering particles on the order of $10^{12}$ particles per $\mathrm{cm}^{2} / \mathrm{sec}$, atomic oxygen reaction rates may be 1.0 and the ram flux $10^{14}$ particles per $\mathrm{cm}^{2} / \mathrm{sec}$ (Tennyson and Morison, 1990). Thus, instead of a time scale of 10 years for sputtering, we might expect a degradation time scale of a few days for atomic oxygen. Indeed, in LEO, only a few weeks are required to destroy a 1-mil (25.4- $\mu \mathrm{m})$ layer of a highly reactive material like kapton (Ferguson, 1990). However, not all materials are reactive in atomic oxygen. For SP-100 LEO missions with orbit times of more than a few days, nonreactive surface materials must be used. 
The atomic oxygen reaction rates and kinetics for a variety of SP-100 materials have been measured by several researchers: Ferguson, 1984; Horton, Eck, and Hoffman, 1989; Banks, Auer, and DeFilippo, 1990. Investigations of the atomic oxygen durability of SP-100 materials and coatings are ongoing in ground tests and will be continued on the EOIM-3 Shuttle flight experiment to be launched in 1992. The materials to be investigated as part of the CSTI Environmental Interactions Program on this flight are listed in the appendix.

\section{LUNAR AND PLANETARY INTERACTIONS}

The interactions of the SP-100 power system with lunar and planetary environments were identified and evaluated at a workshop held in November 1991 at NASA Lewis (Kolecki and Hillard, 1992). Many of the primary interactions were identified. For example, in low Mars orbit, atomic oxygen degradation and arcing to the plasma are of concern as they are for LEO. The findings of the present Environmental Interactions Program will be relevant to these concerns. On the surface of Mars, there are new problems such as Paschen breakdown in low-pressure neutral environments, chemical and electrical interactions with dust, and melting of the Martian permafrost. Some of these concerns may exist for the Moon.

\section{RECOMMENDATIONS}

The SP-100 power system design requires that the resistance between the SP-100 structure ground and the payload structure ground be high enough to ensure that the payload structure ground will be $100 \mathrm{~V}$ negative of the SP-100 structure ground. Therefore, in the user interface module (UIM), where the structures are attached, there will be a $100-\mathrm{V}$ difference in the structure potentials. The structures must be connected with an insulating material thick enough to stand off the $100-\mathrm{V}$ difference.

In LEO plasma, attention must be paid to materials and geometries in the UIM joint in order to prevent arcing at conductor-insulator junctions. Because conductors known to have a plasma arcing threshold higher than $100 \mathrm{~V}$ must be used, plasma testing to identify such materials should be done. Also, there is some evidence that arc rates are higher for materials that absorb/adsorb water and/or other volatile materials. Such materials should not be used in the UIM joint.

Geometry can influence plasma arcing as well. Thus, geometries that help to prevent ions from entering the conductor-insulator region are preferred.

To avoid arcing during LEO missions, payload surfaces should not utilize exposed conductors or exposed conductor-insulator junctions. For GEO missions, fully conductive surfaces should be used everywhere to avoid differential charging.

For LEO missions, sulfuric acid anodization should be used as an insulating surface in regions where thermal control is not an overriding concern. Also, atomic-oxygen-protected, aluminized kapton blankets (kapton surface on the outside) with a 1000-V dielectric strength should be used on all other outside surfaces of the payload.

Whenever long life is required in a high-plasma-density environment such as low planetary orbits, surfaces should be insulated to prevent the sputtering of high-potential conductors in the plasma.

Wherever micrometeoroids, debris, or manufacturing defects produce small pinholes in insulators, the sputtering rate will be greatly increased by ions focusing into the pinholes. Underlying conductors must 
be sufficiently thick to withstand puncturing at accelerated sputtering rates. Materials with low sputtering rates may also be used if they satisfy thermal, atomic oxygen, structural, and other requirements. Optical, thermal, or other specialized coatings in the line of sight to the sputtering pinhole will become coated with the sputtered material over a long period of time. Such coated surfaces should be placed out of the direct line of sight.

For SP-100 missions with LEO orbit times of more than a few days, surface materials that do not react with high-energy atomic oxygen must be used. 


\section{APPENDIX-SP-100 SAMPLES ON EOIM-3 SHUTTLE FLIGHT EXPERIMENT}

Niobium-1 zirconium

Tungsten-niobium composite

PWC-11

Rokide C

Europium oxide

Indium tin oxide

Molybdenum

Type 304 stainless steel

Udimet 720

Polycarbonate

FEP on kapton

Space suit outer fabric

FEP Teflon

Kevlar
Inconel 718

Molybdenum-13 rhenium

GE Black

BN Point Type A

Brass

Tungsten

6061-T6 aluminum

Diamondlike film

Polypropylene mesh

Viton fabric

Kapton

Space suit fabric upside down

Titanium

Nomex 


\section{REFERENCES}

Banks, B.A.; Auer, B.M.; and DiFilippo, F.: Atomic Oxygen Undercutting of Defects on SiO2 Protected Polyimide Solar Array Blankets. Materials Degradation in Low Earth Orbit (LEO): Proceedings of the Symposium, 119th Annual Meeting of the Minerals, Metals, and Materials Society, V. Srinivasan and B.A. Banks, eds., TMS, Warrendale, PA, 1990, pp. 15-33.

Brewer, R.: System Design and Performance Characteristics. SP-100 Reference Flight System System Design Review, vol. 1: Systems, General Electric Co., Astro-Space Div., 1988. p. 1.8-31.

Eck, T.G.: Sputtering by Low Energy Ions. Submitted to Phys. Rev. Lett., 1992.

Eck, T.G.; Chen, L.-Y.; and Hoffman, R.W.: Sputtering of Ions from Cu and Al by Low Energy Oxygen Ion Bombardment. Proceedings of the Fifth Annual Workshop on Space Operations, Applications and Research (SOAR '91), vol. 2, K. Krishen, ed., NASA CP-3127, 1991, p. 716.

Ferguson, D.C.: The Energy Dependence and Surface Morphology of Kapton Degradation Under Atomic Oxygen Bombardment. Proceedings of the 13th Space Simulation Conference, J. Stecher, ed., NASA CP-2340, 1984, pp. 205-221.

Ferguson, D.C.: The Voltage Threshold for Arcing for Solar Cells in LEO-Flight and Ground Test Results. NASA TM-87259, 1986.

Ferguson, D.C.: Solar Array Arcing in Plasmas. Proceedings of the Third Annual Workshop on Space Operations, Automation and Robotics (SOAR '89), S. Griffin, ed., NASA CP-3059, 1989, p. 509.

Ferguson, D.C.: Atomic Oxygen Effects on Refractory Materials. Materials Degradation in Low Earth Orbit (LEO): Proceedings of the Symposium, 119th Annual Meeting of the Minerals, Metals, and Materials Society, V. Srinivasan and B.A. Banks, eds., TMS, Warrendale, PA, 1990, pp. 97-105.

Ferguson, D.C.; Snyder, D.B.; and Carruth, R.: Findings of the Joint Workshop on Evaluation of Impacts of Space Station Freedom Ground Configurations. NASA TM-103717, 1990.

Frezet, M., et al.: Assessment of Electrostatic Charging of Satellites in the Geostationary Environment. ESA J., vol. 13, no. 2, 1989, pp. 89-116.

Grier, N.T.; and Domitz, S.: Measured Current Collection for High Temperature and High Voltage Power Cables Used in Earth Orbit. Presented at the Aerospace Sciences Meeting of the AIAA, Reno, Nevada, Jan. 1989.

Grier, N.T.; and Domitz, S.: Experimental Breakdown of Selected Anodized Aluminum Samples in Dilute Plasmas. Proceedings of the Fifth Annual Workshop on Space Operations, Applications and Research (SOAR '91), vol. 2, K. Krishen, ed., NASA CP-3127, 1991, pp. 703-709.

Herr, J.L.: A Charging Study of ACTS Using NASCAP. NASA CR-187088, 1991.

Horton, C.C.; Eck, T.G.; and Hoffman, R.W.: Pulsed Ion Beam Investigation of the Kinetics of Surface Reactions. J. Vac. Sci. Technol. A, vol. 7, May-June 1989, pp. 2143-2146.

Jongeward, G.A., et al.: Analysis of SP-100 Environment Interactions. Maxwell Labs., Inc., La Jolla, CA, NASA Contract NAS3-23881, 1987. 
Jongeward, G.A., et al.: Analysis of SP-100 Environment Interactions II. Maxwell Labs., Inc., La Jolla, CA, NASA Contract NAS3-23881, 1990.

Josloff, A.: Summary of Key Systems Requirements. SP-100 Reference Flight System System Design Review, vol. 1: Systems, General Electric Co., Astro-Space Div., 1988a, pp. 1.5-2.

Josloff, A.: Compliance with Requirements. SP-100 Reference Flight System System Design Review, vol. 1: Systems, General Electric Co., Astro-Space Div., 1988b, pp. 1.17-2.

Katz, I.: Electrical Insulator for Use in Plasma Environment. U.S. Patent \# 4835341, 1989, issued to Maxwell Laboratories.

Kolecki, J.C.; and Hillard, G.B., eds.: Electrical and Chemical Interactions at Mars Workshop, NASA CP-10093, 1992.

Purvis, C.K., et al.: Design Guidelines for Assessing and Controlling Spacecraft Charging Effects. NASA TP-2361, 1984.

Snyder, D.B.; and Herr, J.L.: Fifth Annual Workshop on Space Operations, Applications and Research (SOAR '91), K. Krishen, ed., NASA CP-3127, 1991, pp. 694-698.

Stevens, N.J.: Interactions Between Spacecraft and the Charged Particle Environment. Spacecraft Charging Technology 1978, NASA CP-2071, 1978, pp. 268-294.

Tennyson, R.C.; and Morison, W.D.: Atomic Oxygen Effects on Spacecraft Materials. Materials Degradation in Low Earth Orbit (LEO): Proceedings of the Symposium, 119th Annual Meeting of the Minerals, Metals, and Materials Society, V. Srinivasan and B.A. Banks, eds., TMS, Warrendale, PA, 1990, pp. 59-75.

Upschulte, B.L., et al.: Significant Reduction in Arc Frequency of Negatively Biased Solar Cells: Observations, Diagnostics, and Mitigation Technique(s). Space Photovoltaic Research and Technology Conference 1991 (SPRAT '91), NASA CP-3121, 1991, pp. 32.1-32.9.

Vampola, A.L.: Radiation Effects on Space Systems and Their Modeling. Space Systems and Their Interactions with Earth's Space Environment, Progress in Astronautics and Aeronautics, vol. 71, H.B. Garrett and C.P. Pike, eds., AIAA, New York, 1980, pp. 339-348.

\title{
DISCLAIMER
}

\begin{abstract}
This report was prepared as an account of work sponsored by an agency of the United States Government. Neither the United States Government nor any agency thereof, nor any of their employees, makes any warranty, express or implied, or assumes any legal liability or responsibility for the accuracy, completeness, or usefulness of any information, apparatus, product, or process disclosed, or represents that its use would not infringe privately owned rights. Reference herein to any specific commercial product, process, or service by trade name, trademark, manufacturer, or otherwise does not necessarily constitute or imply its endorsement, recommendation, or favoring by the United States Government or any agency thereof. The views and opinions of authors expressed herein do not necessarily state or reflect those of the United States Government or any agency thereof.
\end{abstract}




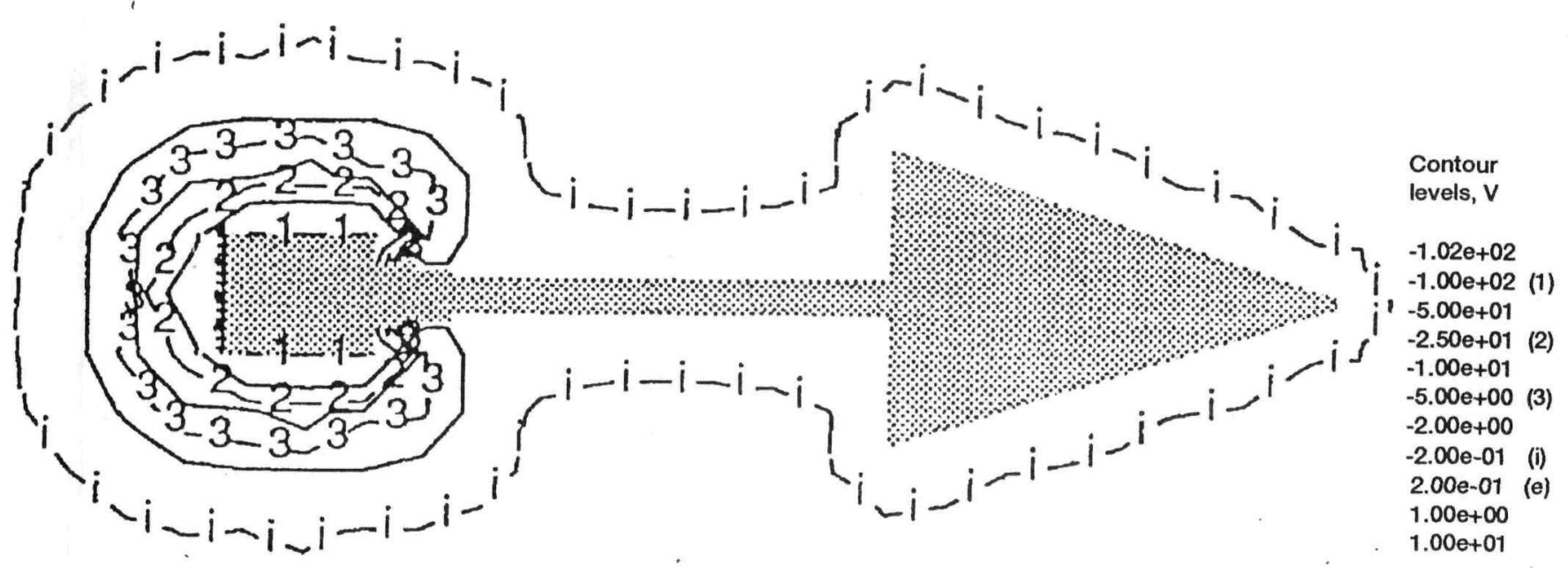

Figure 1. SP-100 floating potential. Load biased to $100 \mathrm{~V}$ negative with respect to body.

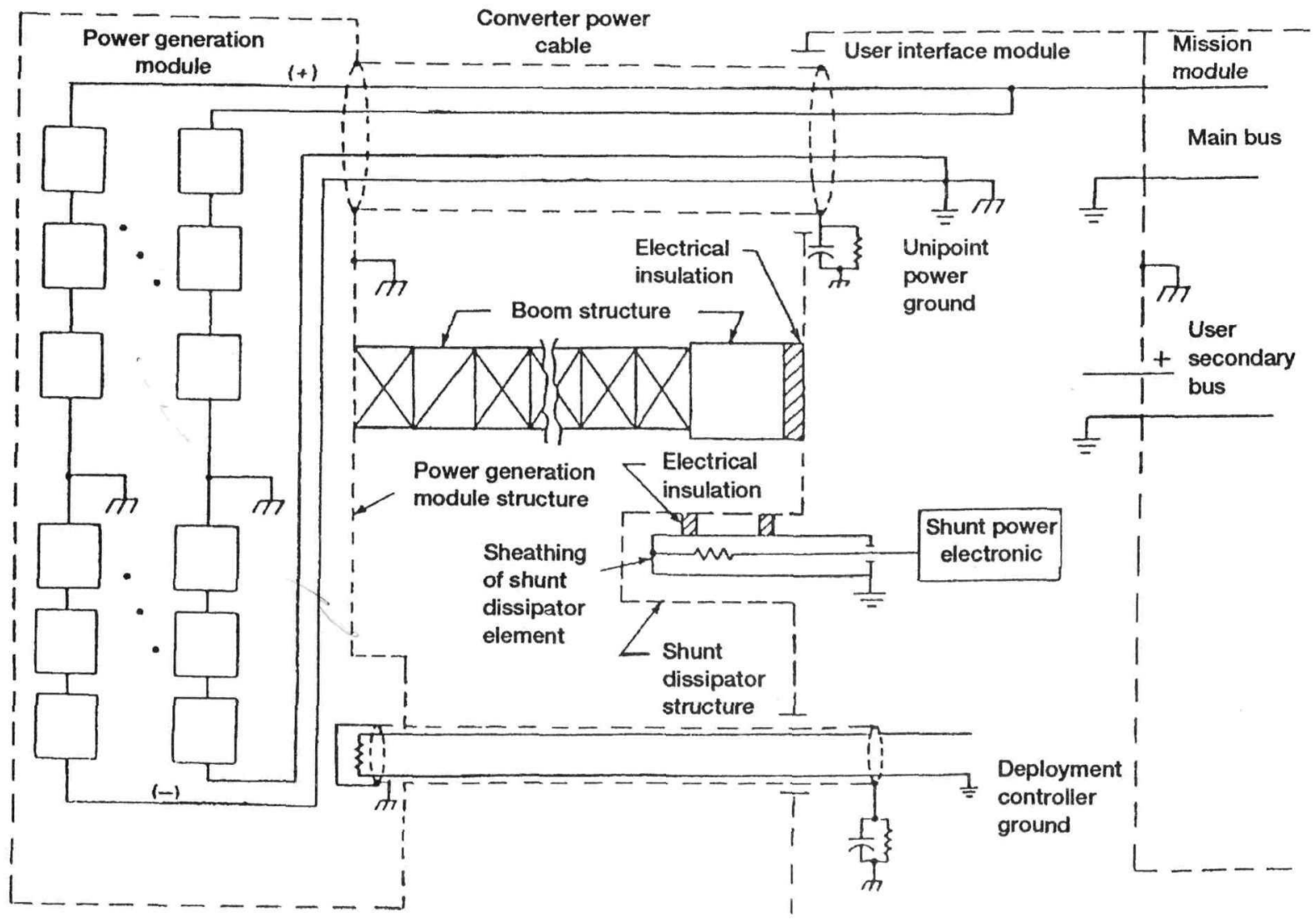

Figure 2.-System design and power grounding. 


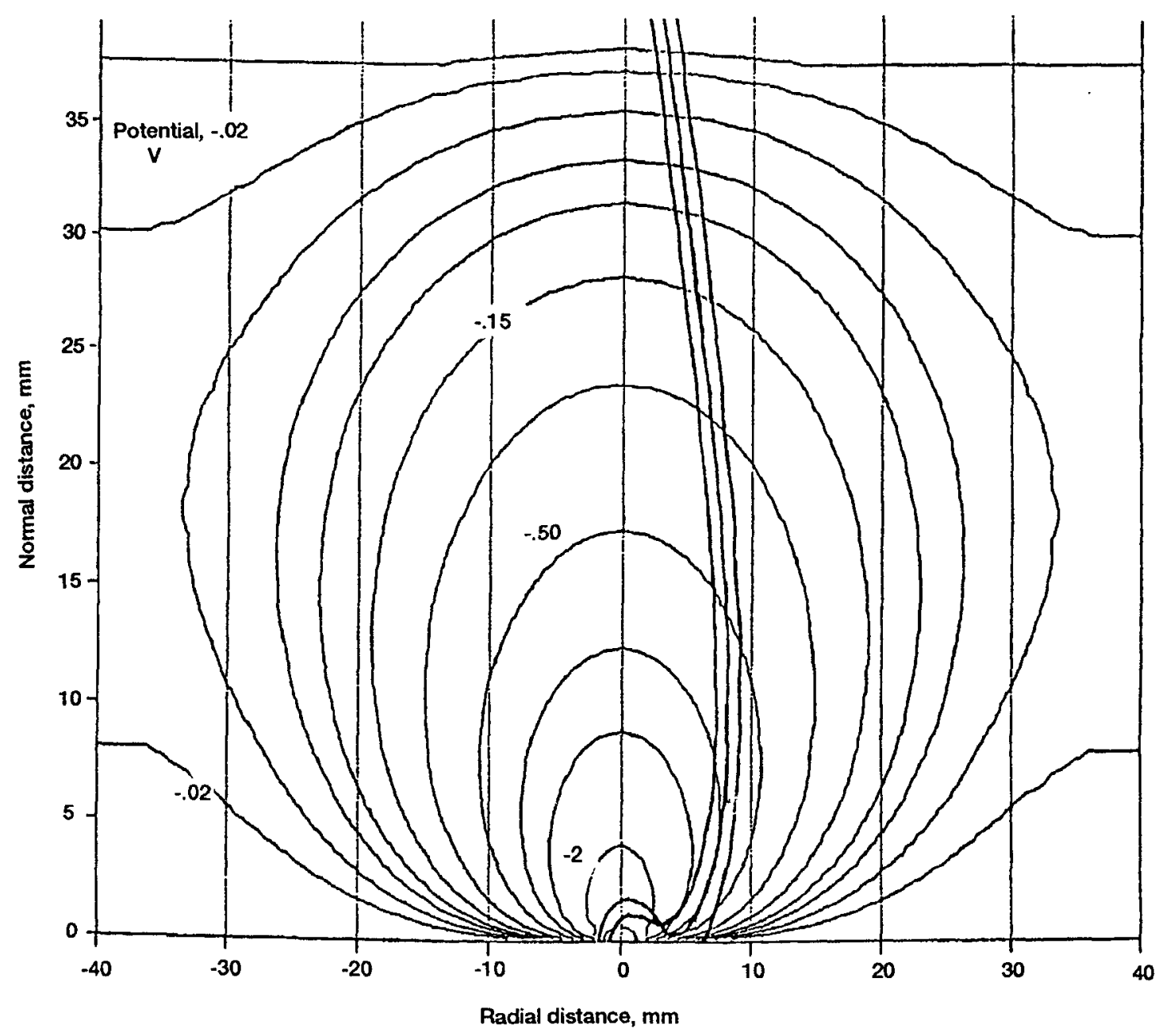

Figure 3. - Equipotentials and ion tracks near a small pinhole. 


\section{REPORT DOCUMENTATION PAGE}

Public reporting burden for this collection of information is estımated to average 1 hour per response, including the time for reviewing instructions, searching existing data sources, gathering and maintaining the data needed, and completing and reviewing the collection of information Send comments regarding this burden estimate or any other aspect of this collection of information, including suggestions for reducing this burden, to Washington Headquarters Servicas, Directorate for information Operations and Reports, 1215 Jefferson Davis Highway, Sulte 1204. Arlington, VA 22202-4302, and to the Office of Management and Budget, Papenwork Reduction Project (0704-0188), Washington, DC 20503
1. AGENCY USE ONLY (Leave blank)
2. REPORT DATE
3. REPORT TYPE AND DATES COVERED
January 1993
Technical Memorandum

\section{TITLE AND SUBTTLE}

Environmental Interactions and the SP-100 Power System

6. AUTHOR(S)

Dale C. Ferguson
WU-590-13-51

8. PERFORMING ORGANIZATION REPORT NUMBER

E-7328

Lewis Research Center

Cleveland, Ohio 44135-3191

10. SPONSORING/MONITORING AGENCY REPORT NUMBEP

National Aeronautics and Space Administration

Washington, D.C. 20546-0001

NASA TM-105866

11. SUPPLEMENTARY NOTES

Responsible person, Dale C. Ferguson, (216) 433-2298.

12a. DISTRIBUTKN/AVAILABILITY STATEMENT

12b. DISTRIBUTION CODE

Unclassified - Unlimited

Subject Category 20

13. ABSTRACT (Maximum 200 words)

Interactions of the SP-100 power system with its expected ambient environments are defined. SP-100 payloads will float $100 \mathrm{~V}$ negative of the low Earth orbit (LEO) plasma. Choice of proper geometries and materials will prevent arcing at conductor-insulator junctions in LEO. Care in selecting surface coatings will prevent dielectric breakdown. Sputtering is a concern for long-duration LEO missions. Atomic oxygen durability of SP-100 materials will be tested in ground and flight tests. Evaluation of SP-100 in lunar and planetary environments has begun. The report of a recent workshop on Chemical and Electrical Interactions on Mars identified many of the primary interactions.

\begin{tabular}{|c|c|}
\hline $\begin{array}{c}\text { 14. SUBJECT TERMS } \\
\text { SP-100; Plasma interactions }\end{array}$ \\
\hline $\begin{array}{c}\text { 17. SECURTY CLASSIFICATION } \\
\text { OF REPORT } \\
\text { Unclassified }\end{array}$ & $\begin{array}{c}\text { 18. SECURTY CLASSIFICATION } \\
\text { OF THIS PAGE } \\
\text { Unclassified }\end{array}$ \\
\hline
\end{tabular}

\begin{tabular}{|c|c|}
\hline & $\begin{array}{c}\text { 15. NUMBER OF PAGES } \\
15\end{array}$ \\
\hline & $\begin{array}{r}\text { 16. PRICE CODE } \\
\text { A03 }\end{array}$ \\
\hline $\begin{array}{l}\text { 19. SECURITY CLASSIFICATION } \\
\text { OF ABSTRACT } \\
\text { Unclassified }\end{array}$ & 20. LIMITATION OF ABSTRACT \\
\hline
\end{tabular}


National Aeronautics and

Space Administration

Lewis Research Center

Cleveland, Ohio 44135

Orticial Dusinose

Penelty for Prtvete Ues $\$ 300$
|||||

ADDRESS CORRECTION REQUESTED

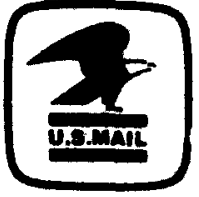

Posiage and $F$ ees $P$ aid National Aeronaulics and Space Administration

NASA 451 